\title{
O PLATONISMO DE RUSSELL NA METAFÍSICA E NA MATEMÁTICA ${ }^{1}$
}

Guido Imaguire*

RESUMO Neste artigo, analiso o surgimento e a superação do Platonismo em B. Russell, tanto na sua filosofia da matemática como na sua metafísica. Começo por explicitar os argumentos que levaram Russell a aderir ao chamado "Platonismo Proposicional" — posição que será tecnicamente relevante na definição de números. Na seção seguinte, discutirei até que ponto a teoria das descrições definidas determina, necessariamente, uma adesão ao nominalismo, e as dificuldades que surgem para o logicismo conseqüentes do abandono do platonismo. Finalmente, mostrarei como a posição madura de Russell caracteriza-se mais como um reducionismo do que propriamente como um nominalismo, e como este é fundado no princípio do mínimo vocabulário.

Palavras-chave Filosofia da Matemática, Metafísica, Russell

ABSTRACT In this paper, I analyze the emergence and the overcoming of Platonism both in Russell's philosophy of mathematics and his metaphysics. I begin by examining the arguments which led Russell to endorse a position that I term "Propositional Platonism" - this position proves to be relevant for Russell's definition of numbers. In the following section, I address the question of the extent to which Russell's theory of descriptions implies the

* Professor do Departamento de Filosofia da Universidade Federal do Ceará. Artigo recebido em março de 2004 e aprovado em março de 2005. guido_imaguire@yahoo.com.

1 Este artigo é resultado de uma pesquisa realizada com apoio do CNPq. Agradeço a Matthias Schirn e Valdetônio Pereira de Alencar pela leitura crítica do texto, bem como aos pareceristas desta revista, pelas importantes observações.

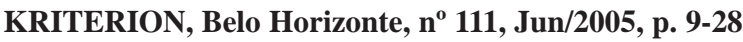


acceptance of nominalism. Moreover, I examine the difficulties which arise for logicism, if it no longer goes hand in hand with platonism. Finally, I argue argue that Russell's mature position is to be characterized as a form of reductionism rather than as a variant of nominalism.

Keywords Philosophy of Mathematics, Metaphysics, Russell

\section{Superação do Idealismo}

Além da influência dos filósofos que dominavam o panorama intelectual britânico no final do século XIX, como H. Joachim, G. F. Stout, Mc Taggart, T. Green, B. Bosanquet e, especialmente, F. H. Bradley, Russell justifica sua curta passagem pelo Idealismo por meio da convicção de que o argumento ontológico para a existência de Deus seria correto (ABR, p. $86^{2}$ ). Essa justificativa, independentemente da questão de ser cogente ou não, revela dois aspectos importantes: (1) que Russell concebia o Idealismo como a doutrina segundo a qual o sujeito cognoscente, de algum modo, tem uma função constitutiva da realidade; e, relacionado a isso, (2) a sua convicção de que conceitos são entidades dependentes desse sujeito.

Mas Russell extrai do próprio Idealismo um princípio que o conduz à sua superação. Segundo seu relato, quando havia alguma disparidade entre as posições de Kant e de Hegel, Russell aderia preferencialmente ao segundo, pois este conseguiu superar o subjetivismo ao qual o primeiro ainda estava subordinado. O princípio da maior objetividade como ideal filosófico foi aplicado na avaliação do próprio Idealismo e levou Russell e Moore ao diagnóstico de subjetivismo e psicologismo na filosofia de Bradley. A superação do subjetivismo idealista se dá na passagem para uma posição que poderia ser designada como Platonismo Proposicional.

Em vários textos (por exemplo, PoM, p. xxiii; MPD, p. 42; ABR, p. 88), Russell atribui a Moore a iniciativa de superação do idealismo. No artigo "The Nature of Judgment" (Mind, abril de 1899), Moore propõe como objeto de análise lógico-filosófica não mais os juízos (judgments) de Bradley, considerados essencialmente subjetivos, mas sim as proposições, concebidas da seguinte maneira:

2 Os textos de Russell utilizados neste artigo são aqui mencionados pelas siglas (constantes nas Referências), com a indicação das páginas consultadas. 
Uma proposição não é composta de palavras, nem de pensamentos, mas de conceitos. Conceitos são possíveis objetos do pensamento, mas isto não é sua definição. Isso significa apenas que eles podem entrar numa relação com um pensador, e para que eles possam fazer algo, eles precisam anteriormente ser algo. É indiferente para a sua natureza que alguém os pense ou não. Eles não são passíveis de mudança; e a relação na qual eles entram com o sujeito cognoscente não implica ação ou reação. Trata-se de uma relação única que pode começar ou se encerrar com uma mudança no sujeito; mas o conceito não é causa nem efeito de tal mudança. (1899, p. 179 grifos no original $)^{3}$

Russell logo adere ao Platonismo Proposicional de Moore. A leitura cuidadosa dos seus textos de 1898 revela uma passagem abrupta dos juízos às proposições. O locus exato dessa reviravolta conceitual é a palestra não publicada "The Classification of Relations", apresentada oralmente em janeiro de 1899 e redigida provavelmente em dezembro de $1898 .{ }^{4}$ Nesse texto, Russell analisa as diferentes características lógicas das relações (transitividade, simetria etc), usando no início a expressão "juízos de relação" e, sem maiores explicações para a mudança, no final, "proposições de relação". Mais do que mera transição conceitual, essa passagem marca o início da fase platonista de Russell.

\section{Platonismo Proposicional}

Por Platonismo, compreende-se, em geral, a concepção filosófica que afirma a existência de entidades abstratas, ou seja, entidades que não são materiais, como objetos físicos, nem espaço-temporais, como eventos ou processos, nem mentais, como representações ou sentimentos. Convém distinguir diferentes formas de Platonismo. Os habitantes nativos do Reino Platônico são as formas puras e os universais, no sentido da tradição metafísica escolástica. Mas este Reino também é abrigo para entidades particulares como números, classes e valores de verdade. O Nominalismo, por sua vez, nega a existência de tais entidades abstratas. A rigor, Platonismo e Nominalismo não são posições metafísicas perfeitamente demarcadas e mutuamente excludentes, mas sim tendências estereotípicas entre as quais se alojam alternativas intermediárias, como, por exemplo, o Conceitualismo de Aristóteles.

O fundamento do Platonismo radical de Russell entre 1898 e 1905 é a afirmação da subsistência de proposições e conceitos. Assim como Meinong e Moore, Russell concebe proposições como complexos não lingüísticos e não

3 Tradução minha, bem como todas as citações de autores estrangeiros ao longo do texto.

4 Perceba-se que o texto em questão é anterior à publicação do artigo de Moore, o que apenas confirma o relato de Russell, segundo o qual a influência de Moore se deu principalmente por meio de conversas (ABR, p. 88). 
mentais, independentes do sujeito cognitivo e lingüístico. Em Meinong's Theory of Complexes and Assumptions (MTCA, 1904) Russell apresenta um argumento simples a favor da subsistência de proposições. Tome-se o exemplo a seguir:

(a) Ontem eu fiz um passeio pela cidade.

(b) $\mathrm{O}$ meu passeio pela cidade ontem foi perigoso.

(c) Ontem eu não fiz um passeio pela cidade.

(d) $\mathrm{O}$ meu passeio pela cidade ontem teria sido perigoso.

Todas estas sentenças tratam da mesma proposição p. (a) afirma p; (b) pressupõe a verdade de $\mathrm{p}$ e lhe atribui uma qualidade; (c) nega p; e (d) nega $\mathrm{p}$ e lhe atribui uma qualidade. A proposição p não é uma entidade mental nem lingüística, pois (b) e (d) não atribuem uma qualidade a um juízo (o juízo não é perigoso, mas sim o passeio pela cidade) nem à sentença (a sentença não é perigosa, mas sim o passeio). Como p tem qualidades mesmo quando não é um fato, conclui-se que p não é nada, pois nihili nullae sunt proprietates (o nada não tem atributos). Uma proposição não é nada, ela subsiste mesmo não sendo atualizada como fato. Além disso, o Ser das proposições falsas é estabelecido pela sua efetividade inferencial. Como nada se segue do nada, mas de proposições falsas pode seguir algo (por exemplo, pelo modus tollens), elas não são nada. Há proposições verdadeiras e falsas assim como há rosas vermelhas e brancas. "Por todas estas razões, nós precisamos admitir que há entidades que não existem, e dentre estas precisam ser postas as entidades que são verdadeiras ou falsas, as quais designo proposições" (TNT, p. 496, grifo no original).

Russell assume assim uma ontologia meinonguiana baseada na distinção entre ser e existir. Na sua teoria de objetos (Gegenstandstheorie), Meinong diferencia três estatutos ontológicos: (1) Existência: objetos no tempo e no espaço; (2) Subsistência: objetos abstratos, relações e proposições verdadeiras; e (3) Objetos não subsistentes: objetos impossíveis, como o círculo quadrado e as proposições falsas.

A omniabrangência do Reino do Ser (Realm of Being) é fundamentada no polêmico argumento da pressuposição de existência, conhecido desde Platão e defendido por Meinong. Qualquer proposição do tipo "A não é" é falsa ou sem sentido, pois pretende enunciar algo sobre A, pressupondo, portanto, que A, de alguma forma, é, e ao mesmo tempo nega o Ser de A. O mesmo não vale para "A não existe", pois esta proposição apenas afirma que A não ocupa lugar no espaço-tempo. Assim Meinong supera o "preconceito em favor do real". Com este argumento são introduzidos no Reino Platônico de subsistentes não apenas 
os universais (eles também podem ocorrer como sujeito de tais proposições), mas também os conceitos e as proposições individuais.

Há um claro aroma transcendental neste argumento: qualquer proposição sobre A tem como condição de significatividade a subsistência A. Esse argumento subjaz o primeiro dos 3 critérios de cidadania no Reino do Ser. Recebe tal cidadania (PoM, 1903, p. 47):

1. tudo que pode ser sujeito de uma proposição;

2. tudo que pode ser contado como um (pode ser enumerado);

3. tudo que pode ser objeto do pensamento.

O primeiro critério simplesmente explicita o resultado do argumento da pressuposição de existência. O segundo decorre do princípio (compartilhado por autores como Frege e Leibniz) da universalidade da aritmética e da lógica. O terceiro critério é baseado no princípio da co-extensionalidade de pensamento e ser, mas evita o idealismo (pelo menos em sua versão subjetivista) ao introduzir uma categoria modal: o que pode ser pensado não é, necessariamente, o que é efetivamente pensado. Cada um destes critérios é co-extensivo aos outros dois. Não se pode predicar sobre algo que não é, nem enumerar algo que não é, nem pensar em algo que não é. Para que algo possa ser sujeito de uma proposição, ou possa ser contado, ou possa ser pensado, é necessário que esse algo subsista.

Russell apresenta também um motivo lógico para a adesão ao Platonismo Proposicional. O Idealismo caiu no subjetivismo ao não reconhecer a irredutibilidade lógica dos predicados diádicos. Russell deriva da irredutibilidade das relações a sua realidade, e desta a sua externalidade. Uma das poucas teses constantes da filosofia de Russell é a de que o reconhecimento da realidade e da irredutibilidade das relações conduz necessariamente à superação do Idealismo. A externalidade das relações, em especial da relação entre o sujeito e o objeto da percepção, da vontade ou da crença, garante a objetividade das proposições:

Quando vejo uma árvore, o meu ver não é o mesmo que a árvore; quando eu desejo que você concorde comigo, o meu desejo não é o mesmo que a sua concordância; quando eu acredito que César atravessou o Rubicão, a minha crença não é o mesmo que o evento. As coisas que são ou podem ser objetos de crença, eu as designo proposições (...) (TNT, p. 494, grifos no original)

Para o Platonismo Proposicional a existência da realidade material é apenas derivada (ontologicamente dependente) da realidade conceitual. Todos os 
conceitos são objetivos e categorialmente similares na medida em que são subsistentes. A existência é apenas um conceito ao lado de outros conceitos como vermelho e mortal. Os conceitos são organizados em complexos assertivos verdadeiros ou falsos, as proposições. A verdade ou falsidade de uma proposição é uma propriedade interna e primitiva. Como as proposições Sócrates é mortal e Sócrates existe são verdadeiras, Sócrates é mortal e existe. O Platonismo Proposicional, devido à postulação da dependência ontológica da realidade material em relação à dimensão conceitual, propõe uma teoria da verdade pouco ortodoxa: a proposição Sócrates existe não é verdadeira porque Sócrates realmente existe, mas sim, ele existe porque a proposição Sócrates existe é verdadeira. Verdade é uma noção logicamente anterior e mais primitiva que atualização espaço-temporal, como se percebe no caso das proposições da matemática, que são essencialmente não existenciais e não correspondenciais. $\mathrm{O}$ mundo material é constituído de proposições existenciais verdadeiras, os fatos:

As pessoas imaginam que se A existe, A é um fato; mas, na verdade, o fato é "a existência de A" ou "que A existe". Coisas deste tipo, i.e. "que A existe", elas próprias não existem: coisas deste tipo chamo proposições, e coisas deste tipo são chamadas fatos quando elas são verdadeiras. (TNT, p. 492, grifos no original)

A designação "Platonismo Proposicional" justifica-se, portanto, porque conceitos e proposições são os filhos primogênitos do Reino do Ser russelliano (ver argumentação semelhante em Makin, 2000, p. 56).

\section{Platonismo Matemático}

A expressão "platonismo matemático" foi cunhada por Paul Bernays no seu artigo de 1935, "Sur le platonisme dans les mathématiques". Além de afirmar a existência de entidades abstratas da matemática, como os números, conjuntos e funções, o platonismo matemático caracteriza-se pela tese de que verdades matemáticas são descobertas e não criadas por meio das provas que as demonstram. Por isso, proposições matemáticas não demonstradas, como, por exemplo, a suposição de Goldbach, são consideradas portadoras de um valor de verdade definitivo, mesmo que ainda não saibamos qual, afinal, a nossa limitação epistêmica é um fato contingente e indiferente para o fato matemático bruto. Suspender o tertium non datur é assim a estratégia fundamental do nominalismo matemático na sua versão construtivista.

Admitido o Platonismo Proposicional, a definição de matemática de Russell em Principles como classe de proposições de implicação formal o conduz inevitavelmente a um platonismo matemático. Pois, se por prova se entende 
uma determinada sequiência de proposições com certas propriedades formais, verdades matemáticas não são criadas, mas sim descobertas — descobre-se, por assim dizer, o "caminho" até elas: "Em suma, todo conhecimento precisa ser descoberto exatamente no mesmo sentido em que Colombo descobriu a Índia Ocidental, e não criamos os números, assim como não criamos os indianos" (PoM, § 427)

O platonismo também traz vantagens técnicas para o logicismo, como por exemplo, na definição de números. Semelhantemente a Frege, Russell define números como conjuntos de conjuntos de mesma cardinalidade. O número 1 é definido como o conjunto de todos os conjuntos unitários (de objetos), o número 2 como o conjunto de todos os conjuntos de pares (de objetos) etc. Mas esse procedimento de definição traz uma dificuldade (IMP, cap. 13). Suponhamos que o universo contenha apenas 9 objetos primitivos. Assim, o número 9 é definido como o conjunto cujo único elemento é o conjunto de todos os objetos que existem. Mas o conjunto que define o número 10 (o conjunto cujos elementos são os conjuntos com 10 elementos) é vazio, pois, como só há 9 objetos, não há nenhum conjunto com 10 objetos. O mesmo ocorre com o 11 e os demais sucessores. Logo, todos os números maiores que 9 seriam idênticos, pois iguais ao conjunto vazio. A aritmética colapsa. Para evitar tal catástrofe aritmética, Russell teria de dispor de um reservatório infinito de objetos.

Uma solução possível seria abdicar da idéia de que os conjuntos básicos só possam conter objetos primitivos e admitir conjuntos de vários níveis diferentes. Assim, Russell analisa uma alternativa que é hoje bem conhecida. No pequeno texto The Axiom of Infinity, de 1904, ele define 0 como o conjunto de coisas que satisfaz uma condição impossível, como, por exemplo, $x^{1} x$. O conjunto assim definido subsiste independentemente da existência de qualquer objeto primitivo. Como todo conjunto com a mesma extensão é idêntico, só existe um conjunto vazio. Logo, poder-se-ia definir o número 1 como conjunto que contém como único elemento o conjunto vazio. Desse modo, já teríamos dois conjuntos, que poderiam ser elementos de um terceiro conjunto, e assim ad infinitum. Ou seja, como na definição de Von Neumann, tem-se:

$$
\begin{aligned}
& 0=\varnothing \\
& 1=\{\varnothing\} \\
& 2=\{\varnothing,\{\varnothing\}\} \\
& 3=\{\varnothing,\{\varnothing\},\{\varnothing,\{\varnothing\}\}\} \\
& \ldots
\end{aligned}
$$

5 Frege formula sua concepção de modo similar: "O trabalho da ciência não consiste em um criar, mas sim em um descobrir de Pensamentos verdadeiros". ("Der Gedanke", p. 50) 
Seria cumprir justiça histórica tributar tal procedimento de definição de números originalmente a Russell, sem pretender com isso, é claro, altercar a honestidade intelectual do redescobrimento de Von Neumann. Aliás, o redescobrimento só foi possível devido ao esquecimento ao qual foi condenado tal procedimento pelo próprio Russell. O seu motivo para rejeitá-lo é, como mostro agora, técnico.

Preocupado com a antinomia, Russell introduz no apêndice de Principles uma forma incipiente da teoria dos tipos lógicos (a forma definitiva foi estabelecida entre 1906 e 1908). Fundamentalmente, tal teoria consiste na distinção de diferentes níveis ou tipos lógicos nos quais se organizam os argumentos que podem ser introduzidos em funções proposicionais, que também são estratificadas, garantindo assim uma formação sintática significativa. Cada função proposicional pertence a um nível lógico específico. Como conjuntos são definidos como totalidades dos argumentos que satisfazem uma dada função proposicional, o resultado será a distinção de diferentes níveis de conjuntos. Se aÎC, então $a$ satisfaz a função proposicional “... é um F" (onde F é o conceito-classe ${ }^{6}$ correspondente a C). Um argumento que satisfaz uma função pertence necessariamente a outro tipo lógico que a própria função. Assim, os conjuntos que são elementos de um determinado conjunto pertencem necessariamente a outro tipo lógico que este último. Não há para a teoria dos tipos lógicos conjuntos mistos. Mas no procedimento de Russell e Von Neumann, anteriormente proposto, cada número é um elemento de todos os números subseqüentes: $1 \in 2,2 \in 3,3 \in 4 \ldots$ e, assim, cada número pertenceria a um outro nível lógico. Conseqüentemente, a função proposicional “... é o número de cadeiras desta sala" pertenceria a diferentes níveis lógicos, dependendo do número atribuído, por exemplo:

Um é o número de cadeiras desta sala.

Dois é o número de cadeiras desta sala.

Mas se a mesma função proposicional “... é o número de cadeiras desta sala" pertence simultaneamente a diferentes níveis lógicos, a teoria dos tipos e a lógica colapsam. Por isso, o reservatório de infinitos objetos primitivos precisa ser garantido de outra maneira. Em Principles (§ 339), Russell se utiliza de diferentes argumentos de caráter platônico para assegurar o necessário

6 Um conceito-classe (class concept) é um conceito que, ocorrendo numa função proposicional, forma uma classe (por exemplo, ser um homem), ao contrário de um conceito de uma classe (concept of a class), que é um conceito que denota uma classe (por exemplo, todos os homens). 
super-povoamento de entidades. O primeiro argumento é uma herança de Platão, no seu diálogo Parmênides: basta supor que o 1 é. Como o Ser atribuído ao 1 não é idêntico ao 1, existem pelo menos duas coisas: o 1 e o Ser. Então, existe o 2. Logo, existem o 1, o Ser e o 2, isso quer dizer: existem 3 coisas. Podemos prosseguir assim ad infinitum.

Um outro argumento é herdado de Bolzano e Dedekind. Esse argumento se baseia no fato de que somente em conjuntos infinitos podemos estabelecer uma correspondência biunívoca entre todos os elementos do conjunto e um subconjunto genuíno dele, como, por exemplo, entre o conjunto dos números naturais e o dos naturais pares. A demonstração da infinitude de entidades no Reino do Ser se dá da seguinte maneira:

\begin{abstract}
Novamente, pode ser provado diretamente, por meio da correlação entre o todo e a parte, que o número de proposições ou conceitos é infinito. Pois para cada termo ou conceito existe uma idéia, a qual é diferente daquilo do que ela é a idéia, mas é, novamente, um termo ou um conceito. Por outro lado, nem todo termo ou conceito é uma idéia. Existem mesas e idéia de mesas; existem números e idéias de números, e assim por diante. Assim, existe uma relação biunívoca entre termos e idéias, mas as idéias são apenas alguns dos termos. Logo, existe um número infinito de termos e de idéias. (Não é necessário supor que as idéias de todos os termos existem, ou que elas fazem parte de alguma mente; basta que elas sejam entidades). (PoM, § 339)
\end{abstract}

Na verdade, para que este argumento seja válido, é necessário supor que os elementos do contra-domínio (a idéia correspondente a cada termo do domínio) sejam também elementos do domínio (sejam um termo) e tenham uma idéia correspondente. Logo, é necessário supor que o domínio contenha idéias de infinitos níveis: idéias de idéias e idéias de idéias de idéias etc. Mas, dada essa hipótese, bastaria supor a existência de apenas um termo que não é idéia.

Claro que o recurso ao mundo do Ser, e não ao mundo de existentes, livra Russell da acusação de que a sua aritmética seria dependente do mundo empírico. Não surpreende, pois, que Russell cante louvores ao refúgio platônico em The Problems of Philosophy (1912, cap. 9): “O mundo do Ser é imutável, fixo, exato, ele é a alegria do matemático, do lógico e do construtor de sistemas metafísicos e de todos que amam mais a perfeição do que a vida". Mas não há paraíso sem serpentes.

\title{
4. A Teoria das Descrições
}

Vale para a metafísica o que vale para a sociedade: quanto maior o número de diferentes etnias reunidas numa comunidade, tanto maior o perigo de conflitos e contradições. Uma interpretação recorrente na literatura 
contemporânea sobre Russell aponta a teoria das descrições ("On Denoting" [OD], 1905) como seu marco pessoal de transição para o nominalismo. Dentre outros, Ayer (Russell 1972, p. 52 et seq.) e Quine (1981) são responsáveis por tal interpretação, embora Quine seja cuidadoso e indique explicitamente traços de platonismo em Russell após 1905 (Quine, 1981, p. 78). A força dessa linha de interpretação reside no próprio uso sistemático que Quine faz da teoria das descrições, ampliando-a para além da intenção original de Russell (por exemplo, em On What There Is). Algumas passagens tardias (1959) de Russell parecem amparar tal interpretação:

Meinong (...) afirmou que alguém pode fazer asserções nas quais o sujeito lógico é "a montanha de ouro", apesar de não existir nenhuma montanha de ouro. Ele argumentou que se você diz que a montanha de ouro não existe, é óbvio que há algo que você afirma não existir - a saber, a montanha de ouro; portanto, a montanha de ouro precisa subsistir em algum nebuloso mundo Platônico do Ser, pois de outro modo a sua asserção de que a montanha de ouro não existe não teria significado. Eu confesso que até o momento em que eu cheguei à teoria das descrições, este argumento me pareceu convincente. (MPD, p. 64)

A teoria das descrições focaliza diretamente o primeiro dos critérios de subsistência: tudo que pode ser sujeito de uma proposição tem Ser. Esta passagem de Russell é, porém, enganosa, pois parece sugerir que não se pode assegurar a subsistência do sujeito lógico de uma proposição. Importa observar, porém, que, a rigor, Russell nunca abdica desse princípio. Nomes próprios lógicos ("isto", "aqui", ...) denotam entidades cuja certeza da existência é garantida, ou, como diria David Pears, cuja afirmação de existência ("isto aqui existe") é uma tautologia referencial.

A novidade de OD consiste propriamente na descoberta de que nem todo sujeito gramatical (sujeito de uma sentença) é, de fato, sujeito lógico (sujeito de uma proposição - compreendendo a proposição como instância de explicitação da verdadeira forma lógica de uma sentença). Embora "o atual rei da França" pareça ser sujeito da proposição "o atual rei da França é careca", na interpretação lógica proposta em OD $-\exists \mathrm{x}(\forall \mathrm{y}(\mathrm{Fy} \leftrightarrow \mathrm{x}=\mathrm{y}) \wedge \mathrm{Gx})-$, ele ocorre como um predicado ("F"). A desconfiança da forma gramatical superficial surgida com a teoria das descrições legitima a interpretação de que a teoria das descrições representa o linguistic turn russelliano, trazendo à luz a convicção de que questões ontológicas são indissociáveis de questões lógico-semânticas.

A ausência de um critério de identidade para entidades meramente possíveis leva-nos a supor que tais entidades também não satisfaçam os outros dois critérios de cidadania no Reino do Ser: poder ser contado como um (afinal, 
quantos possíveis atuais reis da França existem?) e poder ser objeto do pensamento (em qual possível atual rei da França se pensa, no careca ou no cabeludo?). A ausência da unicidade de tais entidades traz consigo o ferimento do princípio do tertium non datur: Para todo $\mathrm{x}$, ou x é um $\mathrm{F}$ ou x é um não-F. Correspondentemente, na teoria dos conjuntos, que é construída a partir da teoria lógica, ou um objeto pertence a um conjunto, ou ao seu complemento. A questão é então: o objeto o atual rei da França pertence ao conjunto dos carecas ou ao seu complemento? Na verdade, tanto a proposição $O$ atual rei da França é careca como $O$ atual rei da França não é careca (correspondente a a $\in \mathrm{C}$ e $\mathrm{a} \notin \mathrm{C}$ ) são falsas. Logo, a expressão "o atual rei da França" não pode denotar um objeto primitivo. ${ }^{7}$

Um segundo motivo apontado por Quine para a rejeição de tais entidades é a indistinção do estatuto ontológico entre 2 e o maior número natural. Como números não são objetos espaço-temporais, ambos têm o mesmo estatuto ontológico: são subsistentes não existentes (também o maior número natural satisfaz, aparentemente, o critério triplo de cidadania no Reino do Ser). Assim, a distinção entre ser e existir não é suficiente para dar conta de um fato fundamental que qualquer matemático precisa reconhecer: não há o maior número natural no mesmo sentido que há o 2. Como a teoria das descrições definidas aponta justamente para o fato de que nem toda descrição realmente denota algo, o maior número natural perde seu asilo no Reino Platônico do Ser.

Um terceiro motivo, que Russell não menciona explicitamente, mas que corresponde às suas investigações naquele tempo, está relacionado à redução da teoria de conjuntos à lógica. Como a teoria dos tipos lógicos é parte da lógica, Russell tinha de determinar exatamente o tipo lógico correspondente a cada expressão lingüística. A expressão "rei da França" pode ocorrer como função proposicional do primeiro nível (... é rei da França) ou como objeto primitivo, quando acompanhado do artigo definido ("o rei da França é ..."). Para superar essa ambigüidade, Russell opta por atribuir a esta expressão o estatuto de função proposicional de primeira ordem, afinal, uma proposição do tipo "Luiz XIV é o rei da França" tem, apesar da sua forma aparente de proposição de identidade, um caráter atributivo, na medida em que "ser rei da França" é uma expressão predicativa. Descrições definidas vazias denotam o conjunto vazio, e não um suposto elemento de algum conjunto.

Vários intérpretes têm salientado nos últimos anos que seria enganoso supor que Russell adere a um nominalismo radical depois de 1905. Hager (Continuity and Change in the Development of Russell's Philosophy, 1994,

7 Ver argumento em Charles Parsons, citado por SMITH, 1985, p. 320. 
p. 37) defende que Russell continua platonista até The Problems of Philosophy (1912), dentre outros motivos, devido a passagens como a anteriormente citada. O engano de Hager é supor que com a teoria das descrições só há uma mudança na teoria da linguagem, sem nenhuma implicação para a ontologia. Makin (The Metaphysicians of Meaning, 2000, p. 52 et seq.), por sua vez, também pretende combater a interpretação tradicional, mas ataca a outra fronte. Segundo Makin, já antes de 1905 Russell negava a subsistência do rei da França, por exemplo no artigo "The Existencial Import of Propositions". De fato, nesse artigo transparece uma rejeição de entidades como o atual rei da França e $a$ diferença entre $A$ e $B$, quando estes forem idênticos. Mas esse artigo foi escrito em julho de 1905 (algumas semanas antes da publicação de "On Denoting"), sendo, portanto, apenas inferível dele que a mudança de Russell não foi uma súbita conversão, mas sim resultado de um processo um pouco mais longo. Aliás, já no fim de 1904, em MTCA ele nega o Ser de uma entidade como a diferença entre A e B, quando A e B são idênticos. No meio do ano de 1905, ele diz explicitamente:

Seja nossa proposição da forma “A é diferente de B”; então se essa proposição for verdadeira, existe uma diferença entre A e B, enquanto se ela for falsa não há diferença. Assim, a diferença entre A e B é uma entidade quando a proposição é verdadeira, mas não no caso contrário. Existem dificuldades acerca deste ponto de vista; pois o conceito "a diferença entre A e B" pode parecer ter um significado perfeitamente claro e definido, mesmo quando não há tal diferença. Mas eu penso que isso pode ser negado, de modo que podemos dizer que quando a proposição é verdadeira, este conceito denota um objeto, o qual é a diferenca entre A e B, e quando a proposição é falsa, o conceito não denota um objeto. (TNT, p. 505, grifos meus).

Embora a interpretação de Quine seja correta no geral, ela é imprecisa na medida em que considera Russell fundamentalmente preocupado com as entidades impossíveis de Meinong: “(...) o Russell de On Denoting (1905) elimina os objetos impossíveis de Meinong" (1981, p. 75) e “(...) nesta ocasião (1905) ele foi motivado pela impossibilidade dos objetos impossíveis de Meinong” (1981, p. 79). Russell menciona, de fato, tais objetos impossíveis em On Denoting, mas eles ocorrem somente na sua argumentação com a função de explicitar por que, de modo geral, objetos não existentes são indesejáveis numa ontologia consistente. A sua teoria lida, em primeira linha, com possíveis não atualizados, como ele expressa explicitamente dois anos mais tarde: "Minhas objeções se aplicam igualmente a objetos como 'a montanha de ouro', que não são impossíveis, mas meramente não existentes. Isso, naturalmente, eu admito; de fato, o objeto que eu particularmente pretendia abolir era 'o atual rei da França', que está no mesmo nível que a montanha de ouro" (EA, 1907, p. 93). 
Por isso, Makin (2000, p. 59) conclui com razão que "ele teria mantido o seu caso contra os objetos não subsistentes de Meinong mesmo se Meinong não tivesse admitido objetos impossíveis". Acerta também Pinto (2001, p. 87) quando diz que "o grande adversário de Russell em On Denoting não é Meinong, mas Frege" (voltaremos a isso mais adiante). Em nenhum momento, nem mesmo no Platonismo radical de Principles ou na fase de transição em An Analysis of Mathematical Reasoning (meados de 1898), há espaço para objetos impossíveis na ontologia de Russell (comparar Makin, 2000, p. 61).

A teoria das descrições não representa, portanto, a derrocada do Reino do Ser, mas sim o início de um controle de imigração. Permanece, pois, a questão: até que ponto a teoria das descrições implica uma adesão ao nominalismo?

Inicialmente, vale salientar que a teoria das descrições implica um eliminacionismo de entidades e não propriamente um reducionismo de categorias. Por reducionismo entendo o ímpeto de redução (eliminação) de uma categoria ontológica a outra mais elementar (lógica, ontológica ou epistemologicamente), como, por exemplo, a redução da (categoria de) substância a um feixe de propriedades (teoria de feixes) ou a redução de universais a um conjunto de tropos similares. Por eliminacionismo compreendo o ímpeto de eliminação de entidades particulares supérfluas, sem que isso implique a redução de toda a categoria da entidade particular eliminada. Pode-se eliminar um particular subsistente como o maior número natural, sem com isso abdicar totalmente de toda categoria de números enquanto objetos abstratos.

Vejamos agora o que ocorre com os números na nova ontologia de Russell. Para isso, observemos, primeiramente, um exemplo mais simples de como reduções definicionais implicam reduções teóricas. Se um termo t pode ser definido com recurso aos termos $\mathrm{t}_{1}, \mathrm{t}_{2}, \ldots, \mathrm{t}_{\mathrm{n}}$, então, em toda proposição na qual t ocorre como sujeito, este pode ser substituído por uma expressão que contém apenas $t_{1}, t_{2}, \ldots, t_{n}$. Se a proposição "minha prima é bela" é parafraseada corretamente com "a filha de um(a) irmão(ã) de um de meus progenitores é bela" então a noção de prima pode ser eliminada em função das noções mais elementares filho, irmão e progenitor. É claro também que os dois primeiros termos relacionais $(\mathrm{xFy}=\mathrm{x}$ é filho de $\mathrm{y}$, e xIy $=\mathrm{x}$ é irmão de $\mathrm{y})$ podem ser reduzidos ao último $(\mathrm{xPy}=\mathrm{x}$ é progenitor de $\mathrm{y}): \mathrm{xFy} \equiv \mathrm{yPx}, \mathrm{e} \mathrm{xIy} \equiv \exists \mathrm{z}(\mathrm{zPx} \wedge$ $\mathrm{zPy} \wedge \mathrm{x} \neq \mathrm{y}$ ). A proposição acima teria assim a forma (onde $a$ é a constante para o "eu" e $B$ é o predicado "ser bela"): $\exists \mathrm{x} \exists \mathrm{y} \exists \mathrm{z} \exists \mathrm{w}(\mathrm{xPa} \wedge \mathrm{yPx} \wedge \mathrm{yPz} \wedge \mathrm{x} \neq \mathrm{z} \wedge$ $\mathrm{zPw} \wedge \mathrm{Bw}$ ).

Algo semelhante ocorre na matemática. Todos os números podem ser definidos como conjuntos de conjuntos equinuméricos. Logo, os números 
podem ser eliminados em termos de conjuntos e da correspondência biunívoca entre conjuntos. Como conjuntos, por sua vez, podem ser reduzidos a funções proposicionais extensionalmente equivalentes, eles também podem ser eliminados. Mais do que uma "teoria sem classes" (no class theory), Russell estabelece nos Principia Mathematica (1910-13) uma teoria sem classes e sem números. A redução da aritmética à teoria de conjuntos e esta à lógica, adicionada ao fato de que, em geral, não se assume algo como a existência de objetos lógicos, favorece a suposição de Dummett (1991, p. 301) de que o logicismo é, em seu caráter, mais nominalista que platonista.

O parágrafo anterior contém uma contaminação modal. Números e conjuntos podem mas não precisam ser definidos dessa maneira. Como uma mera possibilidade teórica pode ter implicações ontológicas tão fortes como um holocausto de entidades subsistentes? A justificativa de Russell para a aplicação da navalha de Ockham é de caráter lógico-metodológico. Em Logical Atomism (LA, 1924, p. 326) ele explica:

Quando algum conjunto de supostas entidades tem propriedades lógicas adequadas, revela-se, em muitos casos, que as supostas entidades podem ser substituídas por estruturas puramente lógicas compostas de entidades que não têm tais propriedades. Neste caso, ao interpretar um corpo de proposições que até o momento se cria ser sobre as supostas entidades, podemos substituir as estruturas lógicas sem alterar qualquer detalhe do corpo de proposições em questão. Isso significa uma economia, pois entidades com propriedades lógicas adequadas sempre são inferidas, e se as proposições nas quais elas ocorrem podem ser interpretadas sem fazer tais inferências, a razão para a inferência falha, e nosso corpo de proposições é assegurado contra a necessidade de um passo duvidoso. O princípio pode ser posto da seguinte forma: "sempre que possível, substitua inferências de entidades desconhecidas por construções de entidades conhecidas".

A regra metodológica é: quanto menor o número de entidades supostas, menor a possibilidade de enganos. A teoria das descrições é um artifício lógico que pode ser usado em favor da economia ontológica. Mas aderir a tal teoria não implica necessariamente uma conversão a um nominalismo radical. Dentre outros, Russell continua admitindo a intuição imediata de formas lógicas.

Mas o que ocorre com os habitantes primogênitos do Reino do Ser, os conceitos e as proposições? Surpreende a escassez das referências de Russell após On denoting a tais entidades, antes tão fundamentais na sua ontologia. Em todo caso, fica claro que ele prefere nesta fase expressões nominalistas como "funções proposicionais" em vez de "conceitos-classes" (Quine 1981, p. 77). De fato, embora a expressão "proposição" ocorra em textos posteriores, ela já não tem mais o sentido platônico de antes. Russell não aponta mais para a subsistência de entidades não mentais e não lingüísticas. Uma ação 
metafisicamente correta exigiria, no mínimo, uma explicação para a extradição destas entidades, antes tão proeminentes.

Na verdade, Russell apresenta uma justificativa para o seu desaparecimento. Esta justificativa, parece-me, é exatamente o motivo da passagem considerada tão obscura na segunda parte de OD, onde ele critica a teoria de Frege. Proposições e conceitos, no sentido do Platonismo Proposicional, são eliminados conjuntamente com o sentido de Frege, alvo explícito do texto. A inclusão de uma crítica a Frege é estranha se a intenção de Russell fosse apenas a de combater a ontologia meinonguiana. De fato, Russell percebe que a tese da subsistência de entidades não existentes exercia na sua ontologia pré-OD uma função semelhante a uma das funções do sentido na teoria semântica de Frege. Ambas as teorias funcionam como garantia da significatividade de expressões sem referência. Para Frege, a expressão "o atual rei da França” tem sentido, mesmo não havendo uma denotação correspondente; para Russell o atual rei da França tem Ser, mesmo que não tenha existência. Em uma correspondência de Russell a Meinong, de 15 de dezembro de 1904, o próprio Russel identifica a sua noção de subsistência com a noção de sentido em Frege:

Até o presente momento acreditava que todo objeto precisaria, num certo sentido, ser, e achava difícil reconhecer objetos sem-Ser. Num caso como o da montanha de ouro ou do quadrado redondo é preciso distinguir entre sentido e referência (de acordo com a distinção de Frege). O sentido é um objeto e tem Ser, enquanto a referência, por outro lado, não é um objeto. (Citado por Smith 1985, p. 348, grifo meu)

Além disso, na passagem acima citada de TNT, a subsistência de não existentes é justificada a partir da noção de significação: "Existem dificuldades acerca deste ponto de vista; pois o conceito 'a diferença entre A e B' pode parecer ter um significado perfeitamente claro e definido, mesmo quando não há tal diferença." (TNT, p. 505, grifo meu)

A rejeição do sentido fregiano representa, a rigor, a superação da teoria da subsistência de conceitos e proposições. Mas a rejeição da subsistência de conceitos traz uma dificuldade técnica para a filosofia da matemática. Os conceitos subsistentes foram usados nos argumentos que garantiam o reservatório de infinitas entidades necessário para a definição dos números. A sua supressão torna os argumentos obsoletos, forçando Russell, assim, a tomar a existência de infinitos objetos como um axioma lógico, que permanece o "calcanhar de Aquiles" do logicismo maduro de Russell. 


\section{Russell Maduro: entre Platonismo e Nominalismo}

Em vários momentos após 1905 Russell faz concessões ao platonismo. Em The Problems of Philosophy (1912) Russell atribui aos universais diádicos (as relações) um tipo de ser diferente do ser atribuído às coisas materiais e do ser da consciência e dos sense data, e afirma que a doutrina das idéias de Platão é uma das teorias com maior sucesso para explicar tal tipo de ser. A posição madura de Russell é, pois, intermediária entre o platonismo e o nominalismo. Em 1943, ao elaborar a resposta às objeções de Feiblemann na coletânea de Schilpp (1986, p. 686), Russell declara: "Eu deprecio slogans. Eu não me descreveria como um nominalista ou como um realista; em relação a qualquer universal proposto, eu o examinaria, e esperaria algumas vezes admiti-lo, outras vezes rejeitá-lo."

A decisão sobre a subsistência ou não de um determinado universal se dá numa análise lógico-semântica. O princípio metodológico fundamental neste procedimento é o de estabelecimento do mínimo vocabulário. Um vocabulário para uma determinada teoria é dito mínimo quando ele satisfaz duas condições: (1) nenhum termo do vocabulário pode ser definido com auxílio dos outros termos do vocabulário; e (2) todas as proposições da teoria podem ser formuladas com todos os termos do vocabulário, mas não com apenas um subconjunto dele. No exemplo citado, um vocabulário com os termos pai, filho, tio, primo etc. poderia ser reduzido ao vocabulário progenitor. Na filosofia da matemática a teoria das descrições torna possível construir um vocabulário mínimo lógico que não contenha os termos "classe", "o" ou os numerais. A existência de uma entidade $\mathrm{x}$ não pode ser consistentemente negada por uma determinada teoria se o termo que denota $\mathrm{x}$ pertence ao vocabulário mínimo desta teoria. Em Russell está, portanto, a origem do famoso princípio de comprometimento ontológico de uma teoria, reafirmado por Quine.

Aplicando esse princípio ao problema dos universais, temos a seguinte situação: os universais são sempre expressos por termos que não são nomes próprios lógicos. De modo geral, em qualquer enunciado ocorre pelo menos um termo universal. Não somente adjetivos e substantivos, mas também verbos como "ver", "amar" e preposições como "em" expressam universais. Logo, universais são presentes em quaisquer proposições. Segundo Russell, Hume e Berkeley não perceberam isso porque ignoraram em suas análises os universais diádicos ou relacionais. Em RUP ("On the Relations of Universals and Particulars", 1911), Russell distingue entre universais que estão em vários lugares ao mesmo tempo (qualidades como vermelho ou quente) e universais que não ocupam nenhum lugar no espaço (as relações). Os universais relacionais 
explicitam melhor a necessidade da sua subsistência na medida em que não podem ser interpretados como objetos particulares descontínuos como os universais monádicos empíricos. Em a fica ao norte de $b$, a expressão "ficar ao norte" denota um universal que subsiste independentemente do pensamento, que não está em nenhum lugar no tempo e no espaço e que não é material nem intencional. Universais não existem, eles "subsistem" ou "têm ser". Pensamentos, sentimentos e objetos materiais existem. $\mathrm{O}$ ser, diferentemente do existir, é atemporal.

Russell defende a impossibilidade de uma rejeição definitiva e absoluta de todo e qualquer universal fazendo uso de um argumento comum aos chamados "filósofos da semelhança" (Price, 1953). A tese nominalista de que os universais são meros nomes não é sustentável, afinal, se um termo geral é aplicável a x e a y, então, mesmo ignorando o fato de que x e y devem partilhar um universal comum, deve subsistir entre x e y uma relação de semelhança, e, então, no mínimo, esta relação é um universal (RUP, p. 107). A relação de semelhança não é mais uma dentre outras relações, mas, sim, mais fundamental, posto que as outras relações como "ter a mesma cor que" ou "estar dentro de" só são aplicáveis (como universais) na medida em que diferentes pares de objetos se relacionam de tal e tal modo.

Este argumento, porém, não permaneceu isento de críticas. Quine rejeitao, pois enquanto o termo "é similar" não aparecer como valor de uma variável quantificada, não há nenhum comprometimento ontológico com uma entidade abstrata correspondente. Pode-se dizer que x e y são semelhantes sem se comprometer com a existência da semelhança de x com y. Para um nominalista como Quine, o argumento comumente usado para a reificação de entidades é falacioso: pode-se dizer "Helena é bela" sem se comprometer com a reificação da entidade abstrata a beleza de Helena. Penso que Russell, ainda que tenha "semantizado" a ontologia com seu princípio do mínimo vocabulário, não concordaria com a semantização radical proposta por Quine. Mesmo sem quantificar existencialmente sobre o predicado diádico da semelhança, a predicabilidade verdadeira de um termo geral aos termos que denotam $a$ e $b$ só pode ser justificada se $a$ e $b$ forem ontologicamente similares. A similaridade tem um fundamento in re.

Price apresenta uma outra crítica em Universals and Resemblance (1953, reimpresso em 1998): do fato de que em qualquer enunciado sempre ocorre pelo menos um termo universal, não podemos inferir que "existam" universais. Seria necessário, para se chegar a tal conclusão, uma premissa adicional, a saber, que todo termo geral denota necessariamente uma entidade universal. "A filosofia dos universais tem simplesmente repetido sempre novamente o 
princípio que deveria ser provado, o princípio de que toda palavra geral representa um universal; adicionando, então, que - o que é óbvio - se este princípio é verdadeiro, a palavra 'semelhança' é um caso deste" (Price, 1953, p. 35, grifo no original)

Para mostrar que a tese de que todo termo geral denota um universal não é correta, Price introduz a distinção entre diferentes níveis de semelhança: existem diferentes semelhanças (de primeira ordem), por exemplo, entre dois objetos vermelhos (digamos $\mathrm{S} 1$ ) e entre dois objetos redondos (digamos S2). Se S1 e S2 são ambas relações de semelhança, então existe entre elas também uma relação de semelhança, porém de segunda ordem. Com outras palavras, a própria universalidade é um universal. Assim, a universalidade é uma instância de si mesma. Mas isso é contraditório, pois uma instância de um universal é ipso facto um particular. Tal crítica é, parece-me, falaciosa. Se admitimos, como Price, que existem diferentes níveis de semelhança, como ele faz, então não é correto afirmar que a universalidade é uma instância de si mesma. $\mathrm{Na}$ verdade, a universalidade de primeira ordem seria, então, uma instância da universalidade de segunda ordem. Um particular é uma instância de um universal de primeira ordem, e não há nada de contraditório em se supor que uma universalidade de primeira ordem seja uma instância de um universal de segunda ordem.

Em suma, orientado pelo princípio de economia ontológica, Russell procura avançar em direção ao Nominalismo, tomado como ideal regulativo epistemológico: quanto menor o número de entidades pressupostas, mais segura é uma teoria. A decisão entre Platonismo e Nominalismo permanece, nesse sentido, aberta. A convicção de Russell, de que a lógica é mais fundamental do que a metafísica, justifica-se, dentre outros motivos, porque o avanço em direção ao Nominalismo é resultado do desenvolvimento dos procedimentos eliminativos na lógica: "até que ponto é possível seguir na direção do nominalismo, isso é, para mim, uma questão não resolvida que, se pode ou não ser completamente resolvida, de qualquer forma, só pode ser investigada com uso da lógica matemática". (PoM, introdução à 2. ed., p. Xix).

\section{Referências}

\section{Obras de Russell}

The Autobiography of Bertrand Russell. [ABR] [1967]. London: Allen and

Unwin. (Em alemão: Bertrand Russell - Autobiographie. Zürich: Suhrkamp, 1972.)

. The Axiom of Infinity. [AI] [1904]. In: . Collected Papers 4.

London/New York: Routledge and Kegan Paul, 1994. 
. The Collected Papers of Bertrand Russell. 1990-1994. reimpr. London/ New York: Routledge, 1992. v. 2. (The McMaster University Edition, Unwin Hyman, 1990. 1. impr.).

. The Collected Papers of Bertrand Russell. Foundations of Logic 1903-

1905. London/ New York: Routledge and Kegan Paul, 1994. v. 4. (Ed.: A. Urquhart.) . An Analysis of Mathematical Reasoning. [AMR] [1898]. In:

Collected Papers 2. London/New York: Routledge, 1992.

. The Classification of Relations. [CR] [1899]. In: . Collected

Papers 2. London/New York: Routledge, 1992.

. Essays in Analysis. [EA] [1907]. Lackey (Ed.). London: Allen and Unwin, 1973.

. The Existential Import of Propositions. [EIP] [1905]. In:

Collected Papers 4. London/ New York: Routledge and Kegan Paul, 1994.

. Introduction to Mathematical Philosophy. [IMP] [1919]. reimpr. London:

Georg Allen and Unwin, 1993.

. Logical Atomism. [LA] [1924]. In:

Logic and Knowledge.

London: George Allen and Unwin, 1956.

. Mathematics and Metaphysicians. [1901]. In: Mysticism and

Logic. London/New York: Routledge, 1959.

. My Philosophical Development. [MPD] [1959]. London: Routledge, 1993.

. Meinong's Theory of Complexes and Assumptions. [MTCA] [1904]. In:

. Collected Papers 4. London/ New York: Routledge and Kegan Paul, 1994.

. On Denoting. [OD] [1905]. In: Logic and Knowledge. London:

George Allen and Unwin, 1956

. The Principles of Mathematics. [PoM] [1903]. London: Routledge, 1992.

1912.

. The Problems of Philosophy. [PP] [1912]. London: Home University Library,

. On the Relations of Universals and Particulars. [RUP] [1911]. In:

Logic and Knowledge. London: George Allen and Unwin, 1956.

. The Nature of Truth. [TNT] [1905]. In:

Collected Papers 4.

London/ New York: Routledge and Kegan Paul, 1994.

RUSSELL, B; WHITEHEAD, A. N. Principia Mathematica. [1910-13]. $2^{\text {nd }}$ ed. Cambridge: Cambridge University Press, 1968.

Outras Fontes

AYER, A. J. Russell. London: Fontana/Collings, 1972.

BERNAYS, P. Sur le platonisme dans les mathématiques. (Em alemão: Über den Platonismus in der Mathematik. In: BERNAYS, P. Abhandlungen zur Philosophie der Mathematik. Darmstadt: Wissenschaftliche Buchgesellschaft, 1935.)

DUMMETT, M. Frege - Philosophy of Mathematics. London: Duckworth, 1991.

FREGE, G. Der Gedanke. [1918-1919]. reimpr. In: FREGE, G. Logische Untersuchungen. Göttingen: Vandenhoeck-Reihe, 1993. 
HAGER, P. J. Continuity and Change in the Development of Russell's Philosophy. Dordrecht/Boston/London: Kluwer Academic Publishers, 1994. (Nijhoff International Philosophy Series).

MAKIN, G. The Metaphysicians of Meaning. London: Routledge, 2000.

MEINONG, A. Über Gegenstandstheorie. Selbstdarstellung. [1904]. Hamburg: Felix Meiner, 1988.

MOORE, G.E. The Nature of Judgment. [1899]. reimpr. In: REGAN, T. (Ed.). G. E. Moore — The Early Essays. Philadelphia: Temple University, 1986.

PINTO, P. R. M. Análise argumentativa do texto "On Denoting" de B. Russell. Síntese, v. 28, n. 90, 2001.

PRICE, H. H. Universals and Resemblance. In: INWAGEN, P. V.; ZIMMERMAN, W. Metaphysics: The Big Questions. Oxford: Blackwell, 1953.

QUINE, W. V. Word and Object. Cambridge/Massachusetts: MIT Press, 1960.

. On What There Is. [1948]. In: From a logical Point of View.

Cambridge/Massachusetts: MIT Press, 1953.

Russell's Ontological Development. In: . Theories and Things.

Cambridge/Massachusetts/London: Harvard University Press, 1981.

SCHILPP, P. A. (Ed.). The Philosophy of B. Russell. New York: The Tudor Publishing Company, 1986.

SMITH, J. F. The Russell-Meinong debate. Philosophy ad Phenomenological Research, 45, 1985.

WILLIAM, D. C. The Elements of Being. In: INWAGEN, P. V; ZIMMERMAN, W. Metaphysics: The Big Questions. Massachusetts/Oxford: Blackwell, 1998. 